\title{
Göğüs İncelemelerinde Farklı Tüp Voltajının Tüm Vücut Dozu ve Görüntü Kalitesine Etkisinin Termolüminesans Dozimetrelerle Değerlendirilmesi
}

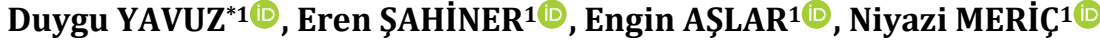 \\ ${ }^{1}$ Ankara Üniversitesi, Nükleer Bilimler Enstitüsü, 06100, Ankara, Türkiye
}

(Alınış / Received: 20.01.2021, Kabul / Accepted: 07.11.2021, Online Yayınlanma / Published Online: 25.12.2021)

\section{Anahtar Kelimeler}

Termolüminesans (TL),

Termolüminesans dozimetre

(TLD),

Dijital Radyografi,

Görüntü kalitesi,

Rando fantom
Özet: Tanısal radyolojide görüntü kalitesi önemli bir rol oynamaktadır. Dijital görüntülemenin, görüntüleri sayısal olarak elde etme, işleme ve saklama gibi avantajları vardır. Dijital dedektörlerin geniş dinamik aralığa sahip olması, daha iyi kalitede görüntülerin elde edilmesine olanak sağlar. Ancak hasta dozunda artışa sebep olabilmektedir. Bu nedenle görüntü kalitesi optimizasyonunun, doz ölçümleri ile beraber yürütülmesi gerekmektedir. ALARA (As Low As Reasonably Achievable) prensibine göre ışınlama, gerekli tanısal bilgileri elde etmek için ayarlanmalıdır ve hastaya verilen radyasyon dozu mümkün olduğunca en az seviyede tutulmalıdır. Bu durum, görüntü kalitesi ve hasta dozu arasında optimizasyon olması gerekliliğini ortaya koymaktadır. Bu çalışmada, dijital radyografide yaygın olarak yapılan göğüs incelemelerinde görüntü kalitesi (Image Quality, IQ) ile hasta dozu arasındaki ilişki araştırılmıştır. Buna bağlı olarak, farklı demet kaliteleri için sabit dedektör dozunda tüm vücut etkin dozu (Effective Dose, ED) ve cilt dozu (Entrance Skin Dose, ESD) hesaplanmıștır. Aynı zamanda farklı tüp voltajlarının ve farklı dedektör dozlarının klinik görüntü kalitesi üzerine etkisi, \% kontrast hesabı ve görünürlük indeksi (Vısıble Index, VI) ile düşük kontrast analizi yapılarak incelenmiștir. Bununla birlikte, termolüminesans (TLD-100, TLD-100H) dozimetrelerinin bu tür çalışmalarda kullanılabilirliği araştırılmıştır. Deneysel ve sayısal olarak elde edilen ölçüm sonuçlarına göre, en düşük tüp voltajı $(70 \mathrm{kVp})$ ile en yüksek tüp voltajı (120 $\mathrm{kVp}$ ) arasındaki kontrast farkı \%67,48 ile \%57,29 aralığında değișmektedir. Azalan tüp voltajı ile fotoelektrik etki daha baskın hale gelir ve saçılan foton miktarı azalır. Saçılan fotonların azalması sayesinde görüntü kontrastında iyileșme gözlenmiștir. Artan tüp voltajı ile görünürlük indeksi (Vısıble Index, VI) değerinin azaldığı görülmüștür ve bu sonuç, azalan tüp voltajlarında görüntü kalitesinin iyileștiği anlamı taşımaktadır. Çalışmanın diğer temel veri kaynağı olan lüminesans dozimetrelerde, TLD-100 ile gerçekleştirilen ölçümlerde, cilt giriş ve cilt çıkış değerleri arasındaki oran 1,24 olarak bulunmuștur. İki değer kıyaslandığında anlamlı bir fark olmadığı gözlenmiştir. TLD-100H'dan elde edilen cilt giriș değeri ile cilt çıkış değeri arasındaki oran ise yaklaşık olarak 17 kattır. Bu sonuç, TLD-100H' in TLD-100'e göre daha yüksek hassasiyetinin olduğunu doğrulamaktadır. Düşük dozun söz konusu olduğu durumlarda ve diagnostik enerji çalışma aralığında TLD$100 \mathrm{H}$ dozimetrelerin daha kullanıșlı olduğu gösterilmiştir.

\section{Evaluation Of Different Tube Voltage Effect On Effectıve Dose and Image Quality For Chest Examınations With Thermoluminescence Dosımeters}

\section{Keywords}

Thermolüminescence (TL),

Thermoluminescence

dosimeter (TLD),

Digital Radiography,

Image Quality,

Rando phantom

\begin{abstract}
Image qualty plays a significant role in diagnostic radiology. Digital imaging has advantages such as obtaining images digitally, processing and storing. The wide dynamic range of digital detectors provides a opportunity to better quality images to be obtained, however, it may cause an increase in patient dose. Therefore, image quality optimization must be performed in conjunction with dose measurements. According to the ALARA (As Low As Reasonably Achievable) principle, irradiation should be adjusted to obtain required diagnostic informations, and the radiation dose to the patient should be kept as low as possible. This situation reveals the requirement of optimization between image quality and. patient dose. In this study, the relationship between image quality and patient dose was investigated in chest examinations, which are performed commonly on digital
\end{abstract}


radiography. Accordingly, whole body effective dose (ED) and entrance skin dose (ESD) was calculated for different beam qualities. At the same time, the effect of different tube voltages and different detector doses on clinical image quality was examined by performing "\% contrast calculation" and low contrast analysis with VI (Visible Index). In the meantime, the usability of thermoluminescent dosimeters (TLD-100, TLD-100H) in such studies has been investigated. According to the experimental and numerical measurement results, the contrast difference between the lowest tube voltage $(70 \mathrm{kVp})$ and the highest tube voltage $(120 \mathrm{kVp})$ varies from $67,48 \%$ to $57,29 \%$. With decreasing tube voltage, the photoelectric effect becomes more dominant and the amount of photons scattered decreases. An improvement in image contrast has been observed by virtue of the fact that scattered photons reduce. It has been observed that the VI value decreases with increasing tube voltage, and this result means that the image quality improves with decreasing tube voltages. In the measurements performed with TLD-100 luminescence dosimeter, which is the other data source of the study, the ratio between skin entrance and skin out values was found to be 1,24 . No significant difference was observed when two values were compared. The ratio between entrance ve out, which is obtained from TLD-100H, is approximately 17 times. This result confirmed that a meaningful result can be obtained with TLD-100H dosimeter and its usage in low dose areas and diagnostic energy range due to their high sensitivity.

\section{Giriș}

Radyoaktivitenin keşfinden hemen kısa bir süreden beri, iyonlaştırıcı radyasyon, hastalıkların tanı ve tedavisi amacıyla yaygın olarak kullanılmaktadır. $\mathrm{Bu}$ kapsamda farklı enerjilerde X-ışınları demetlerinin kullanımı oldukça yaygındır. X-ışınları, vücut içerisinde doku ve organlar ile etkileşerek, farklı diferansiyel azalıma neden olur ve bu azalım farkı, Xışını görüntüleme sistemleri ile anatomik bilgi taşıyan anlamlı bir görüntüye dönüştürülür.

X-ışını içeren tüm radyolojik incelemeler, hastaya radyasyon dozu vermektedir. Radyasyon dozuna maruz kalmanın, belirli bir eşik değeri üzerinde ise deterministik etki olasılı̆̆ını artırdığı bilinmektedir. $\mathrm{Bu}$ sebeple hasta dozu mümkün olduğunca en az seviyede tutulmalıdır. Diğer taraftan, çok düşük ışınlama seviyeleri, görüntü kalitesini önemli derecede azaltmaktadır. Film-ekran sistemlerinde, çok yüksek doz seviyelerinde, görüntü doyuma ulaşarak bozulmaya uğramaktadır. Bu filmlerin bir özelliğidir. Dijital görüntüleme, görüntülerin sayısal olarak elde edilmesi, işlenmesi ve arşivlenmesi açısından avantaja sahiptir fakat bu sistemlerde dozun artması, klinik görüntü kalitesinde iyileşme sağlarken, diğer taraftan hastanın gereğinden fazla radyasyon dozu almasina sebep olabilmektedir [1]. Bu nedenle görüntü kalitesi ve hasta dozu arasında optimizasyon sağlanmalıdır. Dozu azaltmaya yönelik tüm girişimlerde, görüntü kalitesi kritik olduğundan, doz azalımı, tanısal sonucu tehlikeye sokmamalıdır. Sonuç olarak bir radyografik işleyişi optimize ederken görüntü kalitesini takip etmek hayati önem taşımaktadır [2].

Dünyada en sık yapılan tanısal incelemelerin başında gögüs radyografisi gelmektedir. Gögüs bölgesi, farklı anatomik yapılara (kemik, yumuşak doku, hava) sahip olması nedeniyle, teknik olarak en zor incelemelerden biridir. Günümüzde çoğu klinikte göğüs incelemeleri yüksek kilovoltaj tekniği kullanılarak yapılmaktadır. Ancak yapılan çalışmalar incelendiğinde, göğüs incelemeleri için optimum tüp voltajı değerinin daha düşük aralıklarda olması gerektiği vurgulanmıștır [35]. Bu bulgular, hastaya verilen radyasyon dozunun sabit bir görüntü kalitesi seviyesinde azaltılması için kullanılabilir [6]. Buna bağlı olarak, bu çalışmanın amacı, farklı demet kaliteleri ile klinik görüntü kalitesinin değişimini araştırmaktır. Ek olarak çalışmada, görüntü kalitesinin doza bağlı değişimi de incelenmiştir. Farklı dedektör dozlarında görüntüler alınarak, etkin dozdaki değişime karşıllk, klinik görüntü kalitesinin ne kadarlık bir iyileşme gösterdiği kontrast detay analizi yapılarak araştırılmıştır.

Tanısal radyolojide uygun dozimetre kullanımı çok önemlidir. Uygun dozimetreler kullanılarak yapılan doz değerlendirmesi, radyasyondan korunma optimizasyonunda ve tanısal radyolojide özellikle önemlidir. Lüminesans dozimetreler gerek hastaya verilen radyasyon dozunun belirlenmesinde, gerek çalışan personelin maruz kaldığı radyasyon miktarının rutin olarak ölçülmesinde büyük önem taşımaktadır. TLD-100 (LiF:Mg,Ti) ve TLD-100H (LiF:Mg,CuP), küçük boyutlu ve yüksek hassasiyetli dozimetrelerdir. Doku eşdeğeri olmaları ve görüntüyü etkilememeleri sayesinde hasta ya da fantom üzerine rahatlıkla yerleștirilebilmektedirler.

Diagnostik enerji aralığında TLD-100 ile yapılan çalışmalara sıklıkla rastlanırken, TLD-100H ile yapılan çalışmalar oldukça kısıtlıdır. Bu çalışmanın önemli bir diğer amacı ise, kullanılan Termolüminesans dozimetrelerin (TLD-100 ve TLD-100H) düşük doz aralıklarında kullanılabilirliğinin ayrı ayrı incelenmesidir. Bu amaçla, her iki dozimetre uygun okuma parametrelerine göre kalibre edilerek fantom üzerine yerleștirilmiş ve farklı demet kaliteleri için sabit dedektör dozunda tüm vücut etkin dozu 
(Effective Dose, ED) ve cilt dozu (Entrance Skin Dose, ESD) hesaplanmıştır. Yapılan çalışmalar TLD-100H dozimetrelerinin, TLD-100'e göre düşük doz aralıklarında yüksek hassasiyetlerinden dolayı daha etkili olduğunu vurgulamıştır [7, 8].

\section{Materyal ve Metot}

\subsection{Fantomlar}

İnsan eşdeğeri fantomlar, detaylı doz dağılımları elde etmek için yaygın şekilde kullanılmaktadır. Doku eşdeğeri olmaları, kullanım kolaylığı ve dozimetrik özelliklerinin iyi olması bu tür fantomların tercih edilebilirliğini gösterir [9]. Bu çalışmada doz ölçümleri için RANDO fantom ve görüntü kalitesi değerlendirmeleri ile kontrast detay analizi için Polimetil metakrilat (PMMA) fantom kullanılmıştır (Şekil 1). Yetişkin göğüs fantomunun PMMA eşdeğeri Bacher vd. (2005), Honey vd. (2005)'in çalışmalarında $10 \mathrm{~cm}$ kabul edilmiştir [10,11]. Yalçın ve Olğar (2018), Bor vd. (2019) çalıșmalarında SpekCalc.'den hesaplandığında yaklaşık olarak 15 cm'ye karşılık gelmektedir $[12,13]$. Bu nedenle çalışma kapsamında göğüs incelemeleri için, PMMA kalınlığ $15 \mathrm{~cm}$ olarak kabul edilmiştir.

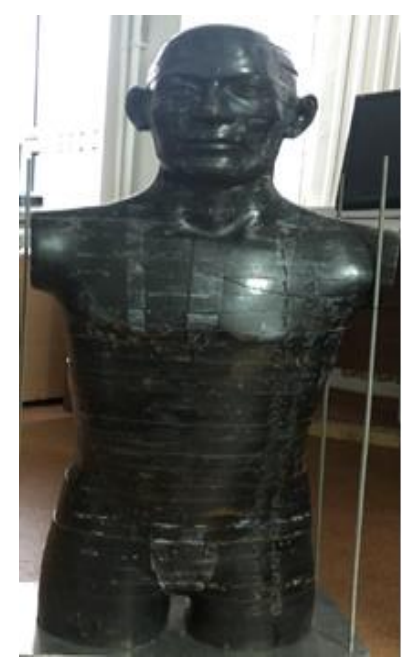

(a)

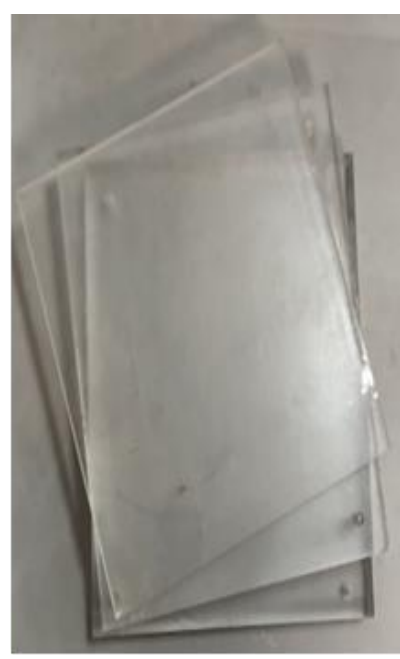

(b)
Şekil 1. Kullanılan fantomlar; a) Alderson RANDO Fantom, b) PMMA Fantom

\subsection{Termolüminesans dozimetreler}

$\mathrm{Bu}$ çalışma kapsamında iki tür termolüminesans dozimetre (TLD-100H ve TLD-100) kullanılmıştır. Her iki dozimetre de aynı boyutlarda olup (3,2 mm x 3,2 mm x 0,9 mm) 55 adet LiF:Mg,Cu,P (TLD-100H) (Şekil 2a) ve 73 adet LiF:Mg,Ti (TLD-100) (Şekil 2b) kullanılmıştır. Dozimetreler Tablo 1'de yer alan okuma parametrelerine göre okunmuştur. Çalışmada Harshaw marka TLD okuyucu sistemi ve bu sisteme bağlı WinREMS yazılım programı, ayrıca TLD'lerin sıfırlanarak tekrar kullanıma hazır hale gelmesi için PTW Marka Tldo Model TLD Fırını kullanılmıştır [14].

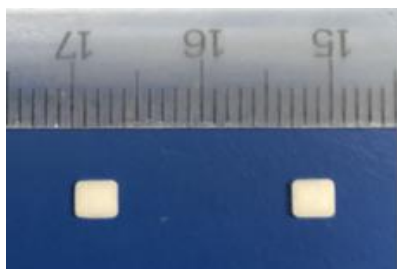

(a)

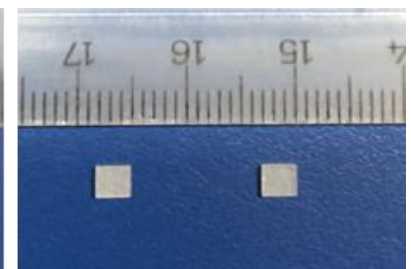

(b)
Şekil 2. Çalışma kapsamında kullanılan TLD’ler; a) TLD100H (LiF:Mg,Cu,P), b) TLD-100 (LiF:Mg,Ti)

Tablo 1. Dozimetrelere ait okuma prosedürü. (TLD-100 için McKeever vd. (1995) çalışmasında önerildiği şekilde kullanılmıştır [15]. Ayrıca TLD-100H için ön ısıtma değeri Lucas vd. (2014) çalışmasında önerildiği gibi uygulanmıştır [16].

\begin{tabular}{ccc}
\hline Okuma & \multicolumn{2}{c}{ Kullanılan Dozimetreler } \\
\cline { 2 - 3 } Prosedürü & TLD-100H & TLD-100 \\
\hline \multirow{3}{*}{ Tavlama } & $240^{\circ} \mathrm{C}^{\prime}$ de 10 & $400^{\circ} \mathrm{C}^{\prime}$ de 1 saat \\
& dakika (firında) & $100^{\circ} \mathrm{C}^{\prime}$ de 2 saat \\
& & (firında) \\
Ön Isıtma & $135^{\circ} \mathrm{C}^{\prime}$ de 10 & $100^{\circ} \mathrm{C}^{\prime} \mathrm{de} 10$ \\
& saniye (cihazda) & dakika \\
& (firında) \\
& Maks. & Maks. \\
Okuma & Sicaklık $=240^{\circ} \mathrm{C}$ & Sicaklık $=300^{\circ} \mathrm{C}$ \\
& Isitma Hız & Isitma Hızl \\
& $\beta=10^{\circ} \mathrm{C} / \mathrm{s}$ & $\beta=10^{\circ} \mathrm{C} / \mathrm{s}$ \\
& Zaman $=13 \mathrm{~s}$ & Zaman $=26 \mathrm{~s}$ \\
\hline
\end{tabular}

\subsection{Görüntüleme sistemi}

Tanı amacıyla kullanılan x-ışını cihazlarının kalibrasyonu ve kalite testleri son derece önemlidir. Kalite kontrol testleri, görüntüleme sistemlerinin performanslarındaki varyasyonları en aza indirerek, standartlara uygun kalitede görüntü elde etmeye olanak sağlar. Kullanılan cihazların kalite testlerinin, uygun prosedürlere göre düzenli olarak yapılması, cihazların yanlış sonuçlar vermesini engellemektedir. Aynı zamanda çalışanların ve hastaların gereğinden fazla doz almalarının da önüne geçilmektedir. Çalışmada, GE Silhouette VR Jeneratör Carestream DRX-1C marka indirekt dijital radyografi kullanılmıştır ve deneysel ölçümler öncesinde, kullanılan X-ışını cihazının kalite kontrol testleri yapılmıştır. Çalışmada kullanılan görüntüleme sisteminin özellikleri aşağıda Tablo 2'de verilmiștir.

Tablo 2. Çalışma kapsamında kullanılan konvansiyonel xışını görüntüleme sisteminin özellikleri

\begin{tabular}{cc}
\hline Jeneratör & GE Silhouette VR \\
Dedektör Marka & Carestream DRX-1C \\
Dedektör Tipi & Flat-Panel Dedektör \\
Dönüștürme Fosforu & Pixelated CsI \\
Piksel Boyutu(mm) & 0,139 \\
X-ıșın Tüpü & Varian RAD-12 \\
Grid Tipi & Sabit \\
Grid Oranı & $10: 1$ \\
Odak-Nokta Boyutu(mm) & $0,6 / 1,2$ \\
Matris Boyutu & $3072 \times 2560$ \\
Doğal Filtrasyon & $>2,5 \mathrm{~mm}$ Al /80kVp \\
kVp/mA & $40-150 \mathrm{kV}$-en fazla 630mA \\
\hline
\end{tabular}




\subsection{Termolüminesans dozimetrelerin kalibrasyon işlemi}

TLD'ler x-ıșın tüpünün odak noktasından $108 \mathrm{~cm}$ uzaklığa yerleştirilerek $80 \mathrm{kVp}, 50 \mathrm{mAs}$ ışınlama parametrelerinde, 20 mGy doz alacak şekilde ışınlanmıştır. Dozimetrelerin birbirlerinden sapmalarını en aza indirmek ve en yakın şiddetteki dozimetreleri seçmek için benzer işlemler $3 \mathrm{kez}$ tekrarlanmıştır. İlk olarak TLD’lerin lüminesans şiddetlerinin (okuma değerlerinin) aynı olması için her bir TLD'ye özgü düzeltme faktörleri element correction coefficient (ECC) bulunmuştur. Son olarak TLD'lerden elde edilen sayım değerinden, soğurulan radyasyon miktarına geçiş için kullanılan reader calibration factor (RCF) değerleri bulunarak kalibrasyon işlemi tamamlanmıștır.

\subsection{Dozimetrik ölçüm yöntemleri}

\subsubsection{Giriş dozu (ESD) ölçümlerinden etkin dozun hesaplanması}

Radyografik ışınlamalarda, cilt giriş dozu (Entrance Skin Dose, ESD) hastanın aldığı dozu belirlemede önemli bir faktördür. Tanısal radyoloji işlemlerinde radyografi başına hasta dozları en iyi şekilde ESD ile tanımlanır. ESD, hasta üzerine yönelen $\mathrm{x}$-ışını demetinin merkezindeki cilt giriş dozunu temsil eder. İyonize radyasyon ile ışınlanan bölgedeki doku ve organlar ile doğrudan etkileşen ve saçlan ışın demetlerinin toplamıdır [17]. Hastanın cildinde ölçülen doz miktarı, daha derindeki dokulardan bir geri saçılım kesri içerecektir. Giriş dozuna bu etki, fantom ya da hasta olmadığında basit hava okumalarının içerisine dahildir. RANDO fantom üzerinde göğüs bölgesine karşılık gelecek şekilde cilt üzerine yerleştirilen TLD'lerden okunan doz değerleri direkt olarak ESD'yi vermektedir. Bu nedenle herhangi bir geri saçılım faktörü uygulanmaz. Çalışmada, etkin doza geçiş için cilt giriş dozu (ESD) yöntemi kullanılmıştır. ESD değerlerinden, etkin doz (ED) değerlerine geçmek için dönüşüm katsayıları kullanılır. Göğüs bölgesi için kullanılan dönüșüm katsayıları Tablo 4'te ESD-ED dönüşüm faktörleri başlığı adı altında verilmiştir [18].

\subsubsection{Göğüs bölgesi için organ dozlarının hesaplanması}

Göğüs bölgesi için belirlenen kritik organlar akciğer, mide ve karaciğerdir. Göğüs bölgesi 10. Kesit ile 24 . Kesit arasında yer almaktadır. RANDO fantom üzerinde her bir organ için belirtilen kesitlerdeki deliklere daha önceden yan yana üç adet TLD gelecek şekilde paketlenip numaralandırılan TLD'ler yerleştirilmiştir. Her TLD okumasından ayrı ayrı doz değerleri elde edilerek organın aldığı toplam doz eşitlik 2.1'de verildiği gibi hesaplanmıştır.

$$
D=\sum F_{i} x D_{i}
$$

$\mathrm{D}=$ Organın aldığ

$\mathrm{F}_{\mathrm{i}}=$ ilgilenilen kesit için kütle ağırlık faktörü

$\mathrm{D}_{\mathrm{i}}=$ Her bir kesit için o kesitte bulunan tüm TLD'lerden elde edilen doz değerlerinin ortalaması

\subsection{Görüntü kalitesi ölçüm yöntemleri}

Görüntü kalitesinin sayısal olarak değerlendirilmesinde göğüs bölgesine karşılık gelen $15 \mathrm{~cm}$ kalınlığındaki PMMA fantom kullanılmıştır. Fantom üzerine farklı boyutlarda ve farklı kalınlıklarda bakır levhalar yapıştırılmıştır (Şekil 3). Dedekte edilebilen en küçük ayrıntıya göre bir görünürlük indeksi (Vısıble Index, VI) değeri hesaplanmış ve düşük kontrast analizi yapılmıştır [11, 19].

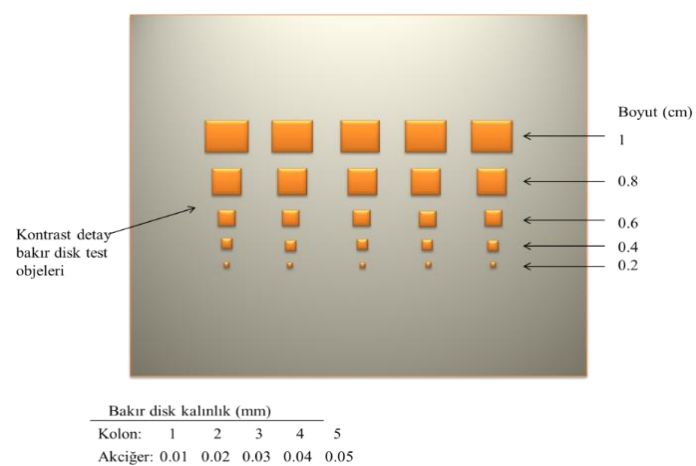

Şekil 3. Görüntü kalitesi değerlendirmesi için hazırlanan PMMA fantomu [20]

Görüntü kalitesi değerlendirmesinin ilk aşamasında, klinik şartlarda farklı demet kalitelerinde RANDO fantom üzerinde akciğer görüntüleri alınarak yüzde kontrast (\%C) değerleri (2) eşitliği kullanılarak hesaplanmiştır.

$$
\% C=\frac{m_{(y . d)}-m_{(k)}}{m_{(y \cdot d)}} X 100
$$

Burada,

$C=$ kontrast,

$\mathrm{m}_{\text {(y.d) }}=$ yumuşak dokudaki ortalama pixel değeri, $\mathrm{m}_{(\mathrm{k})}=$ kemikteki ortalama pixel değeridir.

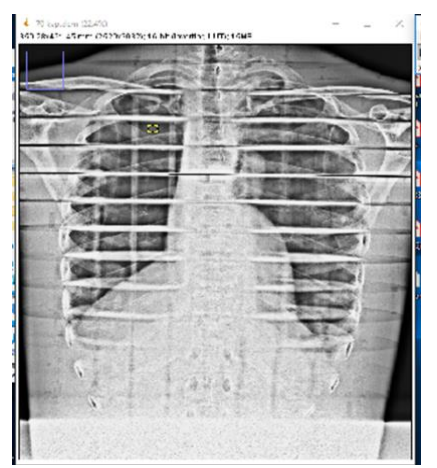

Şekil 4. Kontrast hesabı için alınan akciğer görüntüsü (görüntü 70 kVp, 10 mAs kullanılarak çekilmiștir)

Çalışmada yine görüntü kalitesinin bir göstergesi olarak farklı dedektör dozlarında ve farklı demet kalitelerinde görünürlük indeksi (Vısıble Index, VI), (3) nolu eșitlik kullanılarak hesaplanmıștır. 
Görünürlük indeksi (Vısıble Index, VI), beş farklı detay (bakır) grubunun sayısı $(\mathrm{N})$, referans görüntü ve ilgilenilen görüntüdeki görünür en küçük detay boyutunun eşik kalınlığının ortalamaları alınarak hesaplanmiștır [11, 19]. Görüntü kalitesi değerlendirilmesinin doğru şekilde yaplabilmesi ve hata payını en aza indirebilmek için ışınlama aynı parametrelerde ve aynı koşullarda artarda $4 \mathrm{kez}$ tekrarlanmıştır.

$$
V I=\frac{1}{N} \sum_{A=1}^{N} \frac{\text { Kalınlık }(A)_{\text {image }}}{\text { Kalılılk }(A)_{\text {referans }}}
$$

Referans görüntü verisi olarak klinik şartlarda kullanılan $120 \mathrm{kVp}$ ve 2,5 $\mu \mathrm{Gy}$ dedektör dozu seçilmiştir ve her bir $\mathrm{kVp}$ değerinde $(70 \mathrm{kVp}, 80 \mathrm{kVp}$, $90 \mathrm{kVp}$ ve $100 \mathrm{kVp}$ ) fantom görüntüleri alınarak görünürlük indeksi (Vısıble Index, VI) değerinin sabit dedektör dozunda farklı tüp voltajlarında değişimi incelenmiştir.

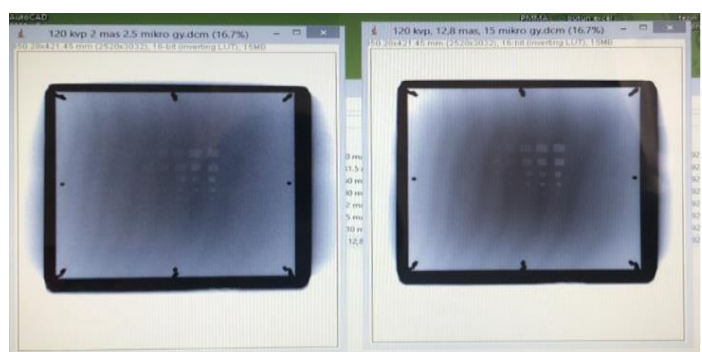

Şekil 5. Görünürlük indeksi (Vısıble Index, VI) hesabı için PMMA fantom üzerinde elde edilen görüntüler

\subsection{X-ışını sistemi kalite kontrol testleri}

Deneysel ölçümlere bașlamadan önce kullanılan xışını cihazının tüp çıkışı kalite kontrol testleri yapılmıştır (Şekil 6). Elde edilen sonuçlar uluslararası raporlarda belirtilen kabul sinırları ile uyumludur [1, $17,21]$.

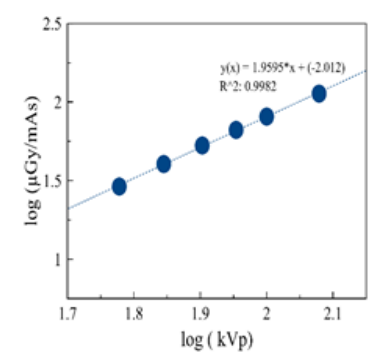

(a)

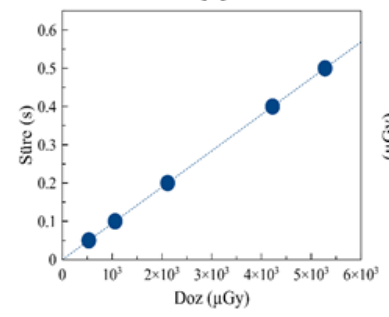

(c)

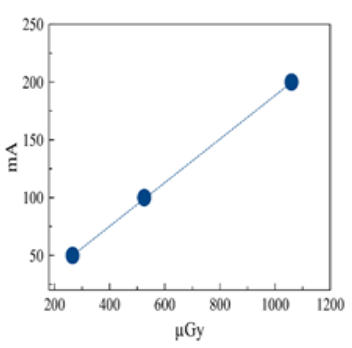

(b)

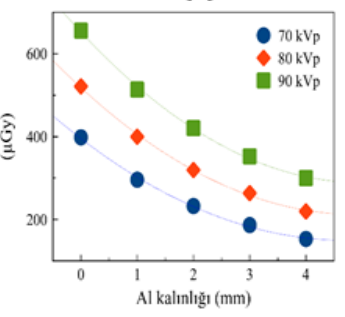

(d)
Şekil 6. Kalite kontrol kapsamında yapılan tüp çıkışı testleri; a) Tüp çıkışının tüp voltajı $(\mathrm{kVp})$ ile değișimi, b) Tüp çıkışının tüp akımı (mA) ile değişimi, c) Tüp çıkışının ışınlama süresi ile değişimi, d) Al kalınlığı - ışınlama grafiği

\subsection{Cilt giriş ve cilt çıkış şiddet değerlerinin bulunması}

Cilt giriş ve çlkış ölçümü için, odak dedektör mesafesi (Focus-Dedector Distance, FDD) $180 \mathrm{~cm}$ olacak şekilde RANDO fantom bucky önüne yerleştirilmiştir (Şekil 7). 3 adet TLD-100H, birbirine değmeyecek şekilde paketlenmiştir. RANDO fantomun cilt girişine ve cilt çıkışına, merkeze gelecek şekilde yerleştirilerek 80 $\mathrm{kVp}, 8$ mAs olacak şekilde ışınlanmıştır.

İkinci aşamada ölçüm, aynı ışınlama koşullarında ve aynı ışınlama parametrelerinde TLD-100 dozimetreleri ile gerçekleştirilmiştir. Elde edilen sonuçlar Tablo 3'de verilmiştir.

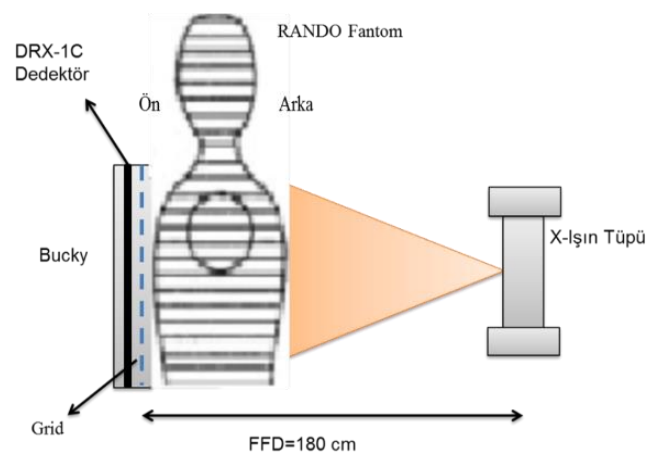

Şekil 7. Çalışmada kullanılan ölçüm geometrisi

\section{Bulgular ve Tartışma}

Çalışmanın ilk aşamasında, RANDO fantom üzerinde cilt girişine ve cilt çıkışına konumlandırılan TLD-100 ve TLD-100H dozimetrelerinden ölçümler alınmıştır. Elde edilen sonuçlar tablo 3'te verilmiştir.

Tablo 3. TLD-100H ve TLD-100 dozimetreleri ile yapılan cilt giriș/cilt çıkıș ölçümü

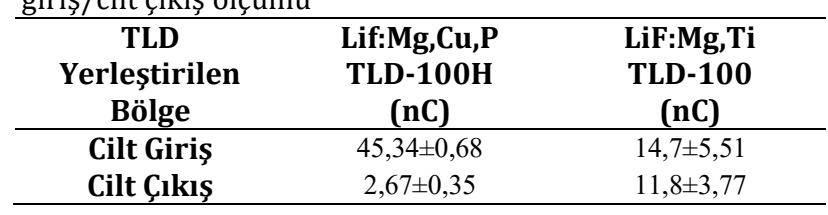

Her iki dozimetre de diagnostik enerji aralığında, aynı parametrelerde ışınlanmasına rağmen, TLD-100 ile gerçekleştirilen ölçümlerde, cildin girişinde ve çıkışında ölçülen değerler arasında anlamlı bir fark olmadı̆̆ı görülmektedir. Cilt giriş ve cilt çıkış değerleri neredeyse aynıdır. Ancak TLD-100H dozimetreleri ile aynı işlemler tekrarlandığında, cilt giriş ve cilt çıkış arasında hata sınırları içerisinde anlamlı bir fark görülmüştür. $\mathrm{Bu}$ sonuç, iki dozimetre arasındaki hassasiyet farkını ortaya koymaktadır. İnsan vücudu farklı anatomik yapılara sahiptir. Vücut içerisinde doku ve organlar ile etkileșen x-ışınları, farklı diferansiyel azalıma sahiptir. Dolayısıyla radyasyon vücut içerisine nüfuz ettikten sonra, farklı doku ve organlar ile etkileşerek azalıma uğrar ve soğurulur. Bu nedenle cilt giriş dozu ile cilt çıkış dozu arasında fark olması beklenir. Şekil 8'de yer alan ışıma eğrileri incelendiğinde, TLD-100 ile yalnızca background 
seviyelerinde (doz ile pik oluşmamış) bir ışıma eğrisi elde edilmiştir. Ancak TLD-100H ile background seviyesinden farklı olarak, dozla ilişkili bir ışıma eğrisi elde edilmiş ve doz değerlendirmesi yapılabilmiștir. $\mathrm{Bu}$ sonuç, TLD-100H dozimetrelerinin, TLD-100 dozimetrelerine göre diagnostik enerji aralığında ve düşük doz alanlarında, yüksek hassasiyetle cevap verdiğini ortaya koymuştur. Bu nedenle çalışmanın diğer kısımlarında TLD-100H dozimetreleri ile devam edilmiştir.

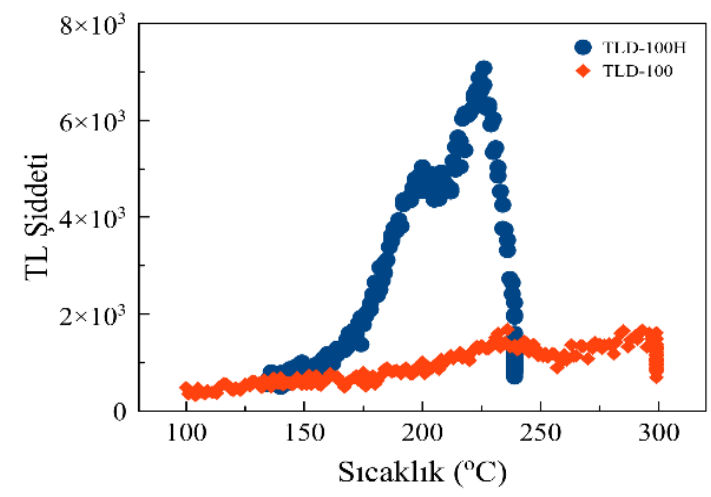

Şekil 8. TLD-100H ve TLD-100 dozimetrelerine ait cilt giriş ve cilt çıkış ölçümlerinden elde edilen ışıma eğrileri (dozimetreler $120 \mathrm{kVp}$ tüp gerilimi, $2 \mathrm{mAs}$ tüp akımında ışınlanmıştır)

Sina vd. (2014) çalışmalarında, cilt giriş dozunun elde edilmesinde TLD-100H dozimetresinin kullanılabilirliğini doğrulamışlardır. TLD-100H ile elde edilen sonuçlar TLD-100 ile kiyaslanmıştır. Çalışmada, tüm TLD'ler standart prodesedürlere (TLD-100H için $240^{\circ} \mathrm{C}^{\prime}$ de 10 dakika, TLD-100 için $400^{\circ} \mathrm{C}^{\prime}$ de 1 saat ardından $100^{\circ} \mathrm{C}^{\prime}$ de 2 saat) göre tavlanmıştır. Elde edilen sonuçlara göre, TLD-100H dozimetrelerinin TLD-100'e göre daha hassas olduğu (sinyal(nC)/doz) ve düşük doz aralıklarında daha etkili oldukları vurgulanmıștır. Düşük doz alanlarında yüksek doz hassasiyetinden dolayı TLD-100H dozimetreleri önerilmektedir [8].

Dong vd. (2002) yaptıkları çalışmada tanısal radyoloji aralığında TLD-100H ve MOSFET'in dozimetrik özelliklerini incelemişlerdir. TLD-100H dozimetreleri ışınlama öncesinde, tanısal radyoloji aralığında kalibre edilmiștir. Geleneksel tanı prosedürlerinde ortalama ESD 20 mGy'in altında olduğu için her iki dozimetre $20 \mathrm{mGy}$ ile ışınlanmıştır. Bizim çalışmamızda da kalibrasyon işlemi için kullanılan TLD'ler 20 mGy doz alacak şekilde ışınlanmıştır. ESD değerlerine ulaşmak için, bizim çalışmamızdan farklı olarak her iki dozimetre geri saçılım ortamını simule eden katı su fantomuna yerleştirilmiștir. Elde edilen sonuçlara göre, kalibrasyon faktörlerinin TLD-100H dozimetrelerine uygulanmasının, özellikle düşük doz alanlarında çok önemli olduğu belirtilmiştir. Bizim çalışmamızda da kalibrasyon faktörleri elde edilen sonuçlara uygulanmıştır. $\mathrm{Bu}$ şekilde TLD hassasiyetinde oluşabilecek varyasyonların önüne geçilmiştir. Çalışmada, TLD-100H dozimetrelerinin 40-125 kvp aralığında yüksek hassasiyet ve düşük enerji bağımlılığı gibi avantajlara sahip olduğu vurgulanmıştır. Düşük doz alanlarında doğrusal yanıt vermeleri TLD'lerin kafatası, göğüs gibi tanısal işlemlerde kullanılmalarını uygun hale getirmiştir [22].

Fernandez vd. (2016) yaptıkları çalışmada, CaSO4:Dy ve TLD-100H disklerinin düşük doz aralığında termolüminesans özelliklerini incelemişlerdir. Hassasiyetin, kullanılan ışınlama parametrelerine göre ciddi derecede değişkenlik göstereceği düșünüldüğünden, elde edilen hassasiyet değerleriyle ilgili sonuçlar literatürle kıyaslanmamıștır. Sonuç olarak, TLD-100H ve CaSO4:Dy'nin tanısal radyolojide kullanılan düşük doz aralığında, ölçümler için uygun olduğu düşünülmüștür ve iyonize radyasyonun kullanıldığı sağlı alanlarında kullanılmaları önerilmiştir [7].

\subsection{Dozimetrik ölçüm sonuçları}

\subsubsection{Cilt giriş dozu (ESD) sonuçları}

Ölçümler, sonuçların tekrarlanabilirliğini ve güvenirliliğini ölçmek için, TLD-100H dozimetreleri kullanılarak, aynı parametrelerde ve koşullarda $3 \mathrm{kez}$ tekrarlanmıștır. TLD'ler, her 3 ölçümde de birbirine çok yakın değerlerde sonuç vermiştir. Bu, TLD'lerin ölçüm hassasiyetinin yüksek olduğu anlamı taşımaktadır. Şekil 9'a göre, artan tüp voltajı ile x-ışın demetinin giriciliği arttığından, cilt girişinde soğurulan düşük enerjili foton sayısı azalmaktadır. $\mathrm{Bu}$ nedenle $120 \mathrm{kVp}$ de en düşük cilt giriş dozu elde edilmiştir.

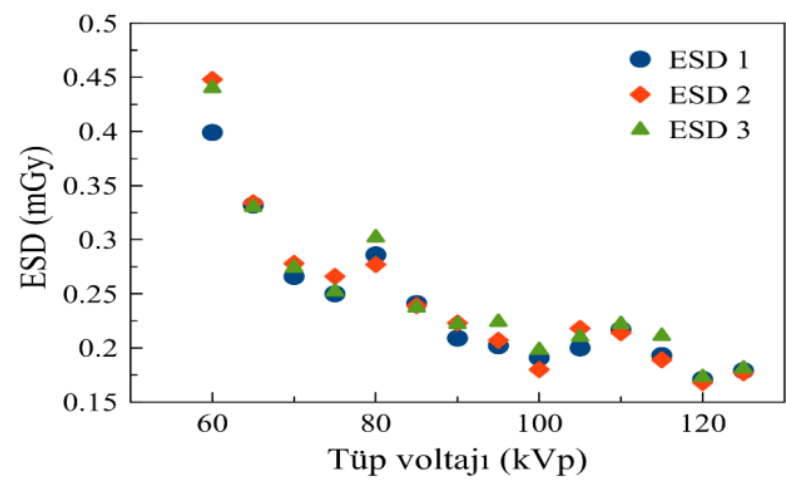

Şekil 9. Cilt giriş dozlarının tüp voltajı $(\mathrm{kVp})$ ile değișimi

\subsubsection{ESD ölçümlerinden elde edilen etkin doz sonuçları}

Çalışmada kullanılan kVp aralığı $(70 \mathrm{kVp}-120 \mathrm{kVp})$ için etkin doz değerleri $0,027 \mathrm{mSv}$ ile 0,028 mSv arasında değişim göstermiştir. Ölçümler klinik koşullar esas alınarak gerçekleştirilmiştir. Bu nedenle 2,5 $\mu$ Gy sabit dedektör dozunda ölçümler alınmıştır. Tüp voltajı artarken, mAs değerleri azaltılmıştır. Böylece $\mathrm{kVp}$ ile mAs'ın birbirini dengelemesi sağlanmıștır. Etkin doz, bütün $\mathrm{kVp}$ değerlerinde mümkün olduğunca aynı tutulmaya çalışılmıştır. mAs 
Tablo 4. ESD yöntemi ile elde edilen etkin dozun tüp voltajı ile değişimi

\begin{tabular}{|c|c|c|c|c|c|c|}
\hline $\begin{array}{c}\text { Tüp } \\
\text { Voltajı } \\
(\mathrm{kVp})\end{array}$ & $\begin{array}{c}\text { Tüp Akımı (mA)x } \\
\text { Işınlama Süresi (s)mAs }\end{array}$ & $\begin{array}{c}\text { Giriş Dozu ESD } \\
\text { (mGy) }\end{array}$ & $\begin{array}{l}\text { *ESD-ED Dönüşüm } \\
\text { Faktörleri [12] }\end{array}$ & $\begin{array}{l}\text { Etkin Doz } \\
\text { ED (mSv) }\end{array}$ & $\begin{array}{c}\text { Eff.Dose } \\
\text { Programı (ED) } \\
\text { (mSv) }\end{array}$ & \%Sapma \\
\hline 70 & 10,0 & $0,273 \pm 0,006$ & 0,100 & 0,027 & 0,030 & $\% 10$ \\
\hline 80 & 8,0 & $0,288 \pm 0,012$ & 0,115 & 0,033 & 0,040 & $\% 17$ \\
\hline 90 & 5,0 & $0,218 \pm 0,008$ & 0,128 & 0,028 & 0,030 & $\% 7$ \\
\hline 100 & 3,2 & $0,190 \pm 0,009$ & 0,142 & 0,027 & 0,030 & $\% 10$ \\
\hline 120 & 2,0 & $0,171 \pm 0,003$ & 0,163 & 0,028 & 0,030 & $\% 7$ \\
\hline
\end{tabular}

değerleri, cihazın izin verdiği belirli mAs aralıklarında ayarlanabildiğinden, tüm kVp'lerde birebir aynı etkin doz elde edilememiştir. Sabit dedektör dozunda, etkin doz değerlerinde gözle görülen bir fark olmamalıdır. Dedektör dozu, her bir $\mathrm{kVp}$ değerinde sabit tutulduğundan $(2,5 \mu \mathrm{Gy})$ ve mAs değerleri etkin doz aynı kalacak şekilde seçildiğinden, etkin doz değerlerinin birbirine olabildiğince yakın çıkması beklenir. Tablo 4'te elde edilen bulgular bunu desteklemektedir.

Tinberg ve Sjöström (2003) farklı görüntü plakaları kullanarak göğüs ve pelvis incelemeleri için etkin doz başına düşen en iyi klinik görüntü kalitesini veren optimum tüp voltajını araştırmışlardır. Çalıșmada 7 mm Al filtre kullanılmıștır. Etkin doz, ilgili dönüșüm faktörleri ile DAP (Dose Area Product)'dan hesaplamıştır. Bu çalışmada etkin doz, ilgili dönüşüm faktörleri kullanılarak ESD yöntemi ile hesaplanmıştır. En düşük tüp voltajında (70 kVp, $32 \mathrm{mAs})$ elde edilen etkin doz (ED) değeri ile en yüksek tüp voltajında (125 $\mathrm{kVp}, 6,3 \mathrm{mAs}$ ) elde edilen etkin doz değeri 18,9 $\mu \mathrm{Sv}$ ile 20,6 $\mu \mathrm{Sv}$ aralığında değişim göstermiştir. Bizim çalışmamızda olduğu gibi seçilen mAs değeri aralıklarına göre ED değeri ufak farklılıklar göstermiştir. Aynı zamanda yapılan çalışmada elde edilen ED değeri tüm kVp'lerde ortalama 19,4 $\mu \mathrm{Sv}$ bulunmuştur. Bizim çalışmamızda ED değerleri ortalama 28,6 $\mu \mathrm{Sv}$ 'dir. Aradaki bu farkın sebebi, yapılan çalışmada $7 \mathrm{~mm} \mathrm{Al} \mathrm{ek} \mathrm{filtre} \mathrm{kullanılmasından}$ ve dedektör dozlarının farklı olmasından kaynaklandığı düşünülmektedir. Çalışmada her iki bölge için de azalan $\mathrm{kVp}$ ile sabit bir etkin doz seviyesinde görüntü kalitesinin arttığı bulunmuştur [4].

\subsubsection{Organ dozu aracılığı ile etkin dozun hesaplanması}

Eşdeğer doz, her bir organ dozunun radyasyon ağırlık faktörü ile çarpılması ile hesaplanmıştır [23]. Farklı tüp voltajlarında elde edilen eşdeğer doz değerleri Tablo 5'te gösterilmiştir.

Akciğer için yapılan doz hesapları en düşük (70 kVp) ve en yüksek (120 kVp) tüp voltajlarında $0,0126 \mathrm{mSv}$ ile 0,0089 mSv aralığında değişim göstermiştir. Organ dozlarının akciğer bölgesinde birbirinden farklılık göstermesi beklenen bir sonuçtur. Çünkü akciğerler havadan oluşmaktadır. Artan $\mathrm{kVp}$ ile demet giriciliği artmaktadır. Dolayısıyla bu, soğurulan dozun azalmasına sebep olmaktadır. Karaciğer bölgesinde elde edilen eșdeğer doz değerleri en düșük tüp voltajinda $(70 \mathrm{kVp}) \quad 0,0028 \mathrm{mSv}$ ve en yüksek tüp voltajında (120 kVp) 0,0022 mSv olarak bulunmuştur. Mide bölgesinde elde edilen eşdeğer doz değerleri ise en düşük ve en yüksek tüp voltajlarında $0,0049 \mathrm{mSv}$ ile 0,0048 mSv arasında değișim göstermiştir. Karaciğer ve mide bölgelerinde belirgin bir artıș azalıș yoktur. Bunun sebebi olarak akciğere göre daha yoğun olmaları düşünülmektedir.

Tablo 5. Hesaplanan eșdeğer doz değerleri

\begin{tabular}{cccc}
\hline Tüp Voltajı & \multicolumn{3}{c}{ Eşdeğer Doz (mSv) } \\
\cline { 2 - 4 } (kVp) & Akciğer & Karaciğer & Mide \\
70 & 0,0126 & 0,0028 & 0,0049 \\
80 & 0,0126 & 0,0025 & 0,0046 \\
90 & 0,0098 & 0,0016 & 0,0056 \\
100 & 0,0091 & 0,0024 & 0,0042 \\
120 & 0,0089 & 0,0022 & 0,0048 \\
\hline
\end{tabular}

Tablo 6'daki sonuçlara göre, organ dozlarından elde edilen etkin doz değerleri, ESD yöntemiyle elde edilen etkin doz değerlerine göre daha düşük çıkmıştır. Bunun sebebi çalışmada, göğüs bölgesinde 3 kritik organın hesaba katılmış olmasıdır.

Tablo 6. Organ dozlarından hesaplanan etkin doz (ED) değerleri

\begin{tabular}{cc}
\hline Tüp Voltajı (kVp) & ED (mSv) \\
70 & 0,0200 \\
80 & 0,0197 \\
90 & 0,0170 \\
100 & 0,0157 \\
120 & 0,0159 \\
\hline
\end{tabular}

\subsection{Görüntü kalitesi ölçüm sonuçları}

Akciğer incelemelerinde yüksek $\mathrm{kVp}$ tekniği kullanılmaktadır. Göğüs bölgesi hareketli organlardan oluştuğundan, yüksek $\mathrm{kVp}$ kullanımı ile ışınlama süresi azaltılabilmektedir. Böylece hareket nedeniyle oluşabilecek görüntü kusurları engellenmiş olmaktadır. 120-140 kVp mertebesindeki tüp voltajlarında, kaburgaların kontrastı azalmaktadır. Bu akciğer alanı altında kalan yumuşak doku yapılarının değerlendirilmesine olanak sağlamaktadır [1]. Ancak geniș dinamik aralık sunan dijital dedektörlerde düșük tüp voltajlarında iyi kalitede görüntü elde edilebilmektedir. Dünyada, akciğer incelemelerinin düşük demet kalitelerinde yapılabileceğine dair çalışmalar mevcuttur $[3,4,19]$.

Şekil 10'a göre, artan tüp voltajı ile görüntü kontrastı düşmüştür. $\mathrm{Bu}$ sonuç, dijital radyografide, genel 
görüntü kalitesinin ve anatomik yapıların değerlendirilmesinde, düşük tüp voltajı tekniğinin kullanımının, daha üstün bir kontrast sağladığını göstermektedir. Buna bağlı olarak düşük tüp voltajı ile görüntü kalitesinin arttığı görülmüştür. Düşük kVp kullanımı, dokularda saçılımın azalmasına ve soğurulmanın artmasına neden olur. Bu durum klinik görüntü kalitesinin iyileşmesine olanak sağlamıştır. Moore ve arkadaşları (2013) klinik gögüs incelemelerinde görüntü kalitesini 50 ile $120 \mathrm{kVp}$ aralığında değerlendirmişlerdir. mAs değerleri yaklaşık olarak 0,011 mSv etkin doz üretecek şekilde ayarlanmıştır. Çalışmada elde edilen sonuçlar, bizim sonuçlarımıza paraleldir. Düşük tüp voltajlarının eşleştirilmiş etkin doz için üstün görüntü kalitesi sağladığı vurgulamıştır [3].

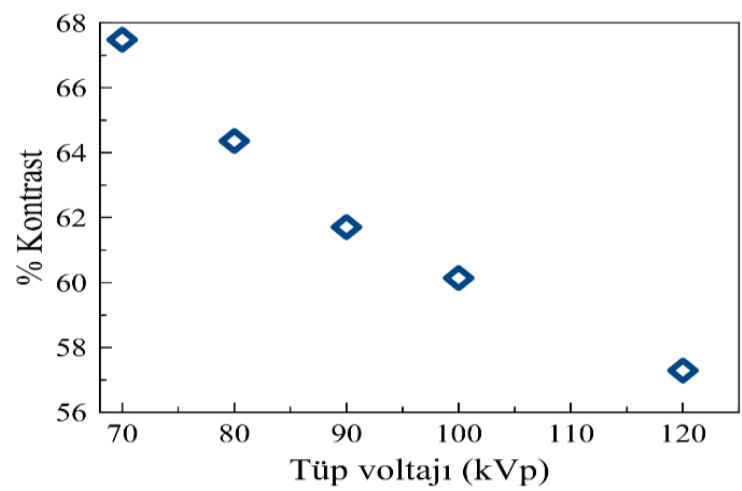

Şekil 10. Kontrastın farklı tüp voltajları ile değişimi

Şekil 11'den elde edilen sonuca göre, görünen en küçük detay boyutuna göre yapılan hesaplamalarda, demet kalitesi arttıkça daha az boyutun seçilebildiği gözlemlenmiştir. Görünürlük indeksi (Vısıble Index, VI) değeri, artan tüp voltajı ile azalmıştır. Bu, azalan tüp voltajlarında görüntü kalitesinin iyileştiği anlamı taşımaktadır.

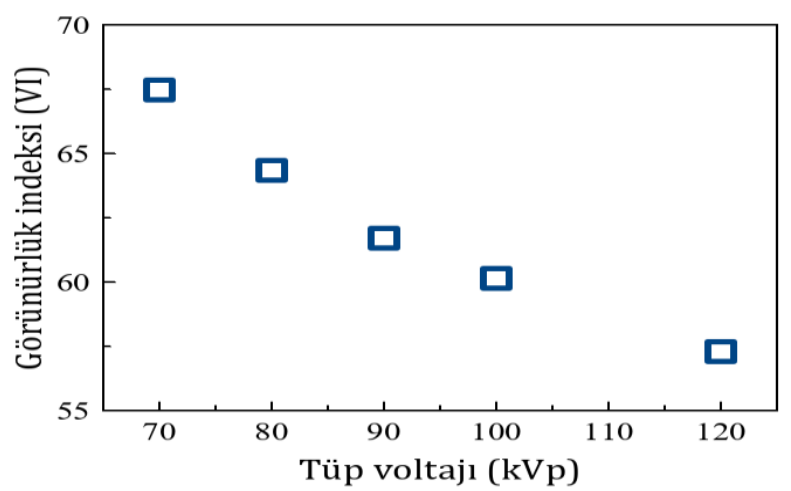

Şekil 11. Görünürlük indeksi (Vısıble Index, VI) değerlerinin sabit 2,5 $\mu$ Gy dedektör dozunda tüp voltajı ile değişim

Tablo 7'ye göre, artan etkin doz ile görünürlük indeksi (Vısıble Index, VI) değerinde artış olduğu görülmüştür. Pascoal ve arkadaşlarının (2005) çalışmalarında, geometrik göğüs fantomu kullanılmıștır. Referans görüntü verisi olarak tüm görüntüleme sistemlerinde $125 \mathrm{kVp}$ ve $4 \mu \mathrm{Gy}$ dedektör dozu belirlenmiştir. 2 ve $8 \mu \mathrm{Gy}$ dedektör dozlarında görüntü kalitesi değişimi incelenmiştir. Bütün sistemlerde, tüm dedektör dozlarında ve ESD ölçümlerinden elde edilen ED değerleri için bir VI görünürlük indeksi hesaplanmıştır. Sonuçlar, tüm sistemlerde ED ile görünürlük indeksinde sürekli bir artış olduğunu vurgulamıştır [19]. Elde edilen sonuçlar, bu çalışmayla uyumludur.

Tablo 7. Görünürlük indeksi (Vısıble Index, VI) değerlerinin dedektör dozu ile değișimi

\begin{tabular}{cccc}
\hline $\begin{array}{c}\text { Tüp Voltajı } \\
(\mathbf{k V p})\end{array}$ & $\mathbf{V I}_{(\mathbf{5} \boldsymbol{\mu G} \mathbf{)})}$ & $\mathbf{V I}_{(\mathbf{1 0 \mu G y})}$ & $\mathbf{V I}_{(\mathbf{1 5 \mu G y})}$ \\
70 & 0,066 & 0,067 & 0,068 \\
80 & 0,063 & 0,065 & 0,067 \\
90 & 0,060 & 0,061 & 0,063 \\
100 & 0,053 & 0,056 & 0,058 \\
120 & 0,050 & 0,056 & 0,060 \\
\hline
\end{tabular}

\section{Sonuç}

Çalışmada, tanısal radyolojide yaygın olarak yapılan göğüs incelemelerinde, farklı demet kalitelerinin görüntü kalitesi üzerindeki etkisi araştırılmıştır. Aynı zamanda göğüs incelemeleri esnasında hastanın aldığı cilt dozu, etkin doz ve göğüs bölgesi için kritik organ dozları hesaplanmıştır.

Tanısal radyoloji, radyoterapi, nükleer tıp gibi medikal sahalarda, hastaların ve personelin maruz kaldığı radyasyon miktarını ölçmede yaygın olarak kullanılan TLD-100 dozimetrelerine ek olarak TLD-100H dozimetreleri kullanılmış ve her iki dozimetreden elde edilen deneysel sonuçlar karşılaştırılmıștır.

$\mathrm{Bu}$ amaçla, uygun okuma prosedürüne göre kalibre edilen TLD'ler rando fantom üzerine yerleştirilerek ESD yöntemi ile cilt giriş ve cilt çıkış dozu hesaplanmiştır. TLD-100 ve TLD-100H dozimetrelerinden elde edilen sonuçlar kıyaslandığında, diagnostik enerji aralığında TLD$100 \mathrm{H}$ dozimetrelerinin hassasiyetinin yüksek olduğunu ve düşük doz aralığında daha etkin olduklarını ortaya koymuştur. Literatürde, dijital görüntülemede, TLD-100H ile yapılmış çalışmalar mevcuttur fakat sınırlıdır. Bu çalışma, TLD-100H dozimetrelerinin düşük doz seviyelerinin bulunduğu alanlarda kullanımının yaygınlaştırılmasına katkı sağlamıştır.

Diğer çalışmaların çıktılarına paralel olarak bu çalıșmada da, etkin doz korunurken azalan tüp voltajı ile görüntü kontrastının arttığı görülmüştür. Aynı zamanda referans görüntü verilerine $(120 \mathrm{kVp}, 2,5$ $\mu G y$ dedektör dozu) göre hesaplanan görünürlük indeksi (Vısıble Index, VI) değeri, azalan tüp voltajı ile sürekli bir artış göstermiştir. $\mathrm{Bu}$ sonuç, göğüs incelemeleri için azalan tüp voltajının görüntü kalitesini iyileştirdiği anlamı taşımaktadır. Ayrıca bu çalışmada, diğer çalışmalardan farklı olarak görünürlük indeksi (Vısıble Index, VI) değerinin farklı dedektör dozları ile değişimi de incelenmiştir. Dedektör dozu arttıkça etkin dozun arttığı ve buna 
bağlı olarak görünürlük indeksi (Vısıble Index, VI) değerinin arttı̆̆ gözlemlenmiştir.

$\mathrm{Bu}$ çalışmanın ileri uygulamaları olarak farklı demet kaliteleri, farklı filtreler, değişen dedektör dozları, TLD-100H'ların farklı diagnostik enerjilere göre davranışları araștırılabilir. Ayrıca mamografi, floroskopi gibi farklı çalışmalarda test edilebilir. Bulgular tartışılan literatürle dozimetrik ölçüm sonuçları yönünden uyum göstermektedir ve Termolüminesans dozimetrelerin bu tür çalışmalarda doz ölçmek için kullanımının önemi vurgulanmaktadır.

\section{Teşekkür}

Çalışmanın görüntüleme kısmında kullanılan deneysel sistemlerin kurulmasındaki desteklerinden dolayı Ankara Üniversitesi Nükleer Bilimler Enstitüsü Öğretim Görevlisi Dr. Asena Yalçın'a teşekkür ederiz. Bu çalışma birinci sıradaki yazarın yüksek lisans tezi kapsamında üretilmiştir

\section{Etik Beyanı}

$\mathrm{Bu}$ çalışmada, "Yükseköğretim Kurumları Bilimsel Araștırma ve Yayın Etiği Yönergesi" kapsamında uyulması gerekli tüm kurallara uyulduğunu, bahsi geçen yönergenin "Bilimsel Araştırma ve Yayın Etiğine Aykırı Eylemler" başlığı altında belirtilen eylemlerden hiçbirinin gerçekleştirilmediğini taahhüt ederiz.

\section{Kaynakça}

[1] IPEM, 2003. Measurement of the performance characteristics of diagnostic X-ray system used in medicine, Part 3, Computed tomography scanners, 2nd edition. Institution of Physics and Engineering in Medicine, New York, Report No:32.

[2] Bacher, K. 2006. Evaluation of image quality and patient radiation dose in digital radiology. Doctoral thesis. Ghent University, p.140, Belgium.

[3] Moore, C.S., Wood, T.J., Beavis, A.W., Saunderson, J.R. 2013. Correletion of the clinical and physical image quality in chest radiography for average adults with a computed radiography imaging system. British Journal of Radiology, 86, 0077.

[4] Tinberg, A., Sjöström, D. 2003. Search for optimal tube voltage for image plate radiography. Conference Paper in Proceedings of SPIE- The International Society for Optical Engineering.

[5] Uffmann, M., Neitzel, U., Prokop, M., Kabalan, N., Weber, M.,Herold, C.J. 2005. Flat-panel-dedector chest radiography: effect of tube voltage on image quality. Radiology, 235;642-650.

[6] Yavuz, D,. 2020. Dijital radyografideki göğüs incelemelerinde farklı Tüp voltajının tüm vücut dozu ve görüntü kaltesine etkisinin araştırılması.
Yüksek Lisans Tezi, Ankara üniversitesi Nükleer Bilimler Enstitüsü. Ankara.

[7] Fernandez, S., Garcia-Salcedo, R., Mendoza, J.G., Sanchez-Guzman, D., Rodrigez, G.R., Gaona, E., Montalvo, T.R. 2016. Thermolüminescent characteristics of Lif:Mg,Cu,P and $\mathrm{CaSO}_{4}$ :Dy for low dose measurement. Applied Radiation and Isotopes, 111, 50-55.

[8] Sina, S., Zeinali, B., Karimipourfard, R.M., Lotfalizadeh, F., Sadeghi, M., Zamani, E., Zehtabian, M., Faghihi, R. 2014. Comparison of the response of TLD-100 and TLD-100H dosimeters in diagnostic radiology. World Academy of Science Engineering and Technology Biomedical and Biological Engineering, Vol: 1, No:9.

[9] ICRP, 1975. International commission on radiological protection. Report the task group on Reference man. Oxford: Pergamon Press. Publication No:23.

[10] Bacher K, Smeets P, Vereecken L, Hauwere AD, Duyck P, De Man R, Verstraete K, Thierens H. 2005. Image quality and radiation dose on digital chest imaging: Comparison of amorphous silicon andamorphous selenium flat-panel system. American Journal of Roentgenology, 187, 630637.

[11] Honey, I.D., MacKenzie, A., Evans, D.S. 2005. Investigation of optimum energies for chest imaging using film-screen and computed radiography. The British Journal of Radiology, 78, 422-427.

[12] Yalçin, A., Olğar, T. 2018. Characterizing the digital radiography system in terms of effective detective quantum efficiency and CDRAD measurement. Nuclear Instruments and Methods in Physics Research Section A: Accelerators, Spectrometers, Detectors and Associated Equipment, 896, 113-121.

[13] Bor, D., Guven, A., Yusuf, A.R., Birgul, O. Yuksel, S., Yalcın, A., Marshall, N., Olgar, T. 2019. A modified formulation of eDQE for digital radiographic imaging. Radiation Physics and Chemistry, 156, 6-14.

[14] Modal 3500 Manuel TLD Reader with WinREMSTM. 2005. Operator's Manuel. Publication No: 3500-W-0-0805-005.

[15] McKeever, S.W.S,. Moscovitch, M., Towsend, P.D. 1995. Thermoluminescence Dosimetry Materials: Properties and Uses. Nuclear Technology Publishing. England.

[16] Lucas, P.A., Aubineau-Laniece, I., Lourenco, V., Vermesse, D., Cutarella, D. 2014. Using LiF:Mg,Cu,P TLDs to estimate the absorbed dose to water in liquid water arround an ${ }^{192} \mathrm{Ir}$ brachytherapy source. Medical Physics American 
Association of Physicist in Medicine, 41, pp.011711.

[17] European Commission Radiation Protection 1997. Criteria for Acceptability of Radiological (Including Radiotherapy) and Nuclear Medicine Installations, European Commission Radiation Protection, Luxembourg. No:91.

[18] Lima, F.R.A., Kramer,R., Vieira, J.W.,Khoury, H.J. 2004. Effective dose conversion coefficients for $\mathrm{X}$-ray radiographs of the chest and the abdomen. International Joint Meeting Cabcun 2004 LAS/ ANS-SNM-SMSR Annual Meeting and XXII SMSR Annual Meeting, July 11-14, Mexico.

[19] Pascoal, A., Lawinski, C.P., Mackenzie, A., Tabakov, S., Lewis, C.A. 2005. Chest radiogtaphy: A comparison of image qality and effective dose using for digital system. Radiation Protection Dosimetry. 114, 273-277.
[20] Mah, E., Samai, E., Peck, D.J. 2001. Evaluation of a quality control phantom for digital chest radiography. Journel of Applied Clinical Medical Physics, 2(2), 90-101.

[21] AAPM, 2002. Quality control in diagnostic radiology, American association of physicists in medicine. United States of America, Report No.74.

[22] Dong, S.L., Chu, T.C., Lan, G.y., Wu, T.H., Lin, Y.C., Lee, J.S. 2002. Characterization of high -sensitivy metal oxide semiconductor field effect transistor dosimeters system and LiF:Mg,Cu,P thermoluminescence dosimeters for use in diagnostic radiology. Applied Radiation and Isotepes, 57, 883-891.

[23] ICRP, 2007. International Commission on Radiological Protection. Publication 103. The Recommendations of international Commission on Radiological Protection. 